\title{
Wa-Tor tridimensional: dinâmica baseada em regras fuzzy para a taxa de predação
}

\author{
Rosana Sueli da Motta Jafelice ${ }^{1}$ \\ FAMAT/UFU, Uberlândia, MG \\ Jefferson Beethoven Martins ${ }^{2}$ \\ Departamento de Informática/IFTM, Uberaba, MG \\ Ana Maria Amarillo Bertone ${ }^{3}$ \\ FAMAT/UFU, Uberlândia, MG
}

Resumo. Uma dinâmica do tipo presa-predador utilizando um autômato celular tridimensional em combinação com um sistema baseado em regras fuzzy é proposta com o objetivo de estender resultados obtidos para o bidimensional. Este sistema interage com as regras do autômato para determinar a taxa de predação dos tubarões que, junto aos peixes, compõem o planeta $W a-T o r$.

Palavras-chave. Modelo Presa-Predador, Autômato Celular 3D, Conjuntos Fuzzy.

\section{Introdução}

Autômatos Celulares (AC) são modelos matemáticos compostos por um conjunto de células dispostas em um espaço $n$-dimensional, em que o estado de uma dada célula em um dado tempo depende de regras locais e de sua relação com sua vizinhança. Introduzido por von Neumann [10] e Ulman, um autômato celular é composto de quatro elementos: um conjunto de estados, um conjunto de células, um tipo de vizinhança e regras de transição. Cada célula apresenta um estado único em um dado tempo $t$, por sua vez, as regras de transição determinam qual será o estado da célula no tempo seguinte $t+1$, de acordo com seu estado atual e o estado das suas células vizinhas. O tempo em um AC avança em passos discretos, e os valores de todas as células são atualizados simultaneamente a cada passo de tempo. Cada célula apresenta um estado único em um dado tempo. O tipo de vizinhança determina quais células são vizinhas de quais outras células. Dois tipos comuns de vizinhança são as de Neumann e de Moore [7]. Esta última é a utilizada neste trabalho e mostrada na Figura 1.

Neste trabalho é construído um autômato celular 3D para um modelo presa-predador que imita a modelagem computacional do bem conhecido "Wa-Tor", Wa por water (água em inglês) e "Tor" pela figura geométrica toro. Esta dinâmica concebida por Alexander Dewdney [5] foi apresentada na edição de dezembro de 1984 da revista americana Scientific American em um artigo de cinco páginas intitulado "Recreações de computador: tubarões e peixes travam uma guerra ecológica no planeta toroidal Wa- Tor". Nas próprias palavras de Dewdney:

O planeta Wa-Tor ... tem a forma de um toro, ou donut, e é totalmente coberto por água. Os dois habitantes dominantes de Wa-Tor são tubarões e peixes.

\footnotetext{
${ }^{1}$ rmotta@ufu.br.

2 jefferson@iftm.edu.br.

3 amabertone@ufu.br.
} 


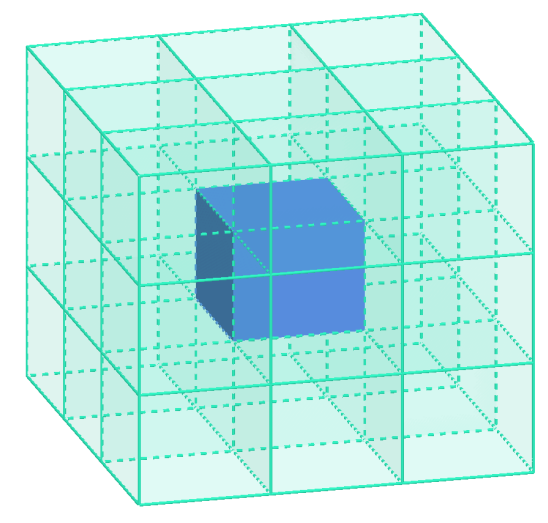

Figura 1: A célula azul escura e suas 26 células vizinhas (em cor azul clara).

Wa-Tor é geralmente implementado como uma grade bidimensional. Neste trabalho o planeta Wa-Tor é definido em um ambiente tridimensional considerado como um hipertoro (a versão tridimensional do toro). De fato, assim como o toro bidimensional pode ser visto como um quadrado completo cujos lados opostos foram identificados, o hipertoro pode ser visto como um hipercubo tridimensional completo cujas faces opostas são identificadas [13]. O cubo é gradeado por células em que se distinguem três cores: a cor verde para peixes, a cor vermelha para tubarões e azul para águas vazias. Os tubarões são predadores e comem os peixes. Tanto os tubarões quanto os peixes vivem, se movem, se reproduzem e morrem. O equilíbrio deste ecossistema é sensível a pequenas perturbações: as populações de duas espécies podem seguir ciclos extremamente diferentes dependendo dos parâmetros dados. Como os ciclos de reprodução e o período de tempo em que um tubarão deve comer para evitar a fome, bem como as posições iniciais de cada ser. Pode ir de ambas as espécies ameaçadas de extinção a uma abundância de uma ou ambas.

Relacionados a este trabalho pode-se encontrar na literatura aplicações do autômato celular em $2 \mathrm{D}[4,5,9,12]$ e em 3D $[1,2,6]$. A novidade desta pesquisa consiste na implementação computacional do autômato no ambiente do software Matlab, com código elaborado pelos autores, que interage com o toolbox fuzzy para a tomada de decisões no ato da predação. De fato, a saída do sistema baseado em regras fuzzy (SBRF) é a taxa de predação a partir da qual o tubarão irá consumir a presa ou perderá essa oportunidade. Uma dinâmica do tipo War-Tor em que as regras são inferidas através de um SBRF, não há na literatura dessa área, até onde os autores tem conhecimento.

A apresentação desta pesquisa é organizada da seguinte maneira: na Seção 2 mostra-se um modelo realístico de uma dinâmica lebres-linces, que serve como validação qualitativa dos resultados dessa pesquisa. Na Seção 3 desenvolve-se a metodologia, detalhando na Subseção 3.1 as regras seguidas na dinâmica do Wa-Tor tridimensional e na Subseção 3.2 a apresentação do SBRF que devolve a taxa de predação dos tubarões para a tomada de decisões da dinâmica presa-predador. Os resultados deste trabalho são apresentados na Seção 4 para, finalmente, compor conclusões e intenções de pesquisas futuras na Seção 5.

\section{Um Modelo Realístico}

Dados obtidos por volta de 1850 de uma companhia americana de peles, em particular de lebres e linces (tipo de felídeos), foram explorados por vários pesquisadores com o objetivo de estudar modelos de interações competitivas entre essas duas espécies.

Sabendo que o número de animais capturados tem sido proporcional à sua população, os pes- 
quisadores descobriram estatísticas dessas duas populações. Entre outras conclusões, destaca-se a convivência forçada dessas espécies analisadas, baseada no fato que os linces se alimentam basicamente de lebres. O ecologista Elton [11] analisou os registros anuais de peles que são apresentados no gráfico da Figura 2.

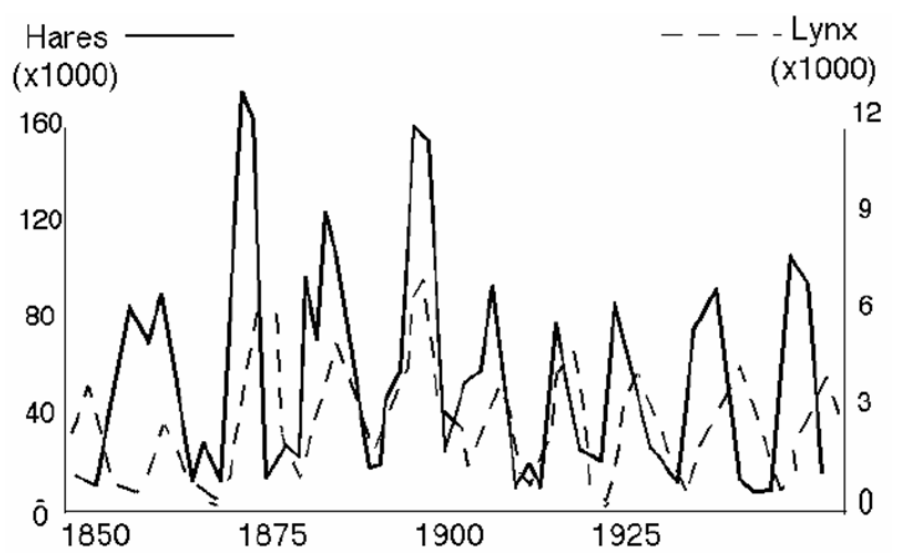

Figura 2: O resultado da pesquisa desenvolvida por Elton nas espécies de lebres (hares em inglês) e linces (linx em inglês). Imagem digitalizada do artigo original [11].

No gráfico da Figura 2 pode se apreciar uma oscilação regular ao longo de dez anos nos números de ambas as espécies. Também pode-se observar que no começo há uma grande quantidade de lebres e pouca de linces que depois estabiliza-se conforme a dinâmica de presa-predador.

Este modelo realístico representado na Figura 2 tem sido utilizado como uma forma de validação qualitativa dos resultados obtidos nesta pesquisa.

\section{Metodologia}

O processo de elaboração da dinâmica do Wa-Tor tem sido dividido em dois tópicos: as regras que governam o autômato celular e as regras fuzzy que determinam a taxa de predação.

\subsection{Regras do Autômato Celular do Wa-Tor}

O comportamento do autômatos celulares possui grande relação com os seus valores iniciais. Para atingir a estabilidade buscada, nesta pesquisa empregou-se um espaço tridimensional com 1728 pontos: 12 elementos em cada um dos eixos coordenados, $x, y$ e $z$. A priori, cento e vinte peixes e oitenta tubarões surgem aleatoriamente, o que representa as condições iniciais da dinâmica. Ao todo, foram executadas 250 iterações, nas quais cada elemento, peixe ou tubarão, efetuará uma ação. No que diz respeito à idade de reprodução, os peixes estarão aptos a cada duas iterações e os tubarões estarão aptos a cada doze. Mesmo que estes parâmetros provenham da análise empírica, há uma certa similaridade com o modelo biológico [3]. Além disso, é importante salientar que os tubarões morrem caso fiquem duas iterações sem alimentação, entretanto os peixes morrem apenas caso sejam ingeridos.

Como já citado, a cada iteração os peixes e tubarões executarão determinada ação e estas atividades em conjunto formarão a dinâmica populacional. No caso dos peixes, é feito um sorteio dentre as 26 possíveis movimentações; considerando os três eixos $x, y$ e $z$. Se o espaço estiver vago, o peixe se moverá para esta nova posição. Além disso, verifica-se se este é o momento de 
reprodução; caso seja, o peixe progenitor deixará um filhote em sua antiga posição. É comum que o sorteio de movimentação do peixe seja feito e o local sorteado esteja ocupado por um peixe ou um tubarão; neste caso o peixe buscará outra posição para tentar se mover. Quando um peixe não conseguir se movimentar é acrescentada uma iteração à sua experiência.

A dinâmica dos tubarões apresenta maior complexidade, pois estes podem se movimentar, reproduzir, adquirir experiência e morrer devido à inanição. Inicialmente é feita uma escolha randômica para decidir em qual das 26 posições será feita uma tentativa de ingestão de um peixe. Caso haja comida na posição sorteada, o tubarão atacará, entretanto o sucesso da empreitada dependerá da sua experiência como predador e da experiência do peixe como presa; o resultado é dado através de um SBRF, a partir do qual se obtém a taxa de predação. Este valor é calculado pela função evalfis, a qual recebe duas variáveis de entrada: o número de reproduções efetuadas pelo peixe em questão e o número de reproduções efetuadas pelo tubarão em questão. Caso a saída deste SBRF esteja acima de 0.5 , o tubarão comerá o peixe e se mudará para a posição do alimento. Salienta-se que a experiência dos peixes e tubarões é baseada na quantidade de reproduções efetuadas. Quando o tubarão não consegue se alimentar apenas nadará. Diante disso, o seu tempo de fome será aumentado para que ele se aproxime mais da morte por inanição. O mesmo princípio será utilizado para que o tubarão escolha o novo possível local: uma escolha randômica é feita e verificar-se-á se o local está livre. Caso esteja, o tubarão ocupará a nova posição e verificará a possibilidade de reprodução. Caso seja a idade certa, o tubarão deixará um filhote em sua antiga posição.

\subsection{Sistema Baseado Regras Fuzzy}

As variáveis de entrada do SBRF são número de reproduções das presas $(\alpha)$ e número de reproduções dos predadores $(\beta)$ e a variável de saída é a taxa de predação dos tubarões. Os termos linguísticos das variáveis de entrada são: Pequeno (P), Médio (Mo) e Grande (G); e da taxa de predação dos predadores são: Baixa (B), Média (Ma) e Alta (A). As funções de pertinências das variáveis de entrada e saída são trapezoidais. Os gráficos dessas variáveis são mostradas na Figura 3 e na Figura 4. Na Tabela 1 apresenta a base de regras fuzzy. O método de inferência fuzzy utilizado é o de Mamdani e de defuzzificação é o Centro de Gravidade [8].
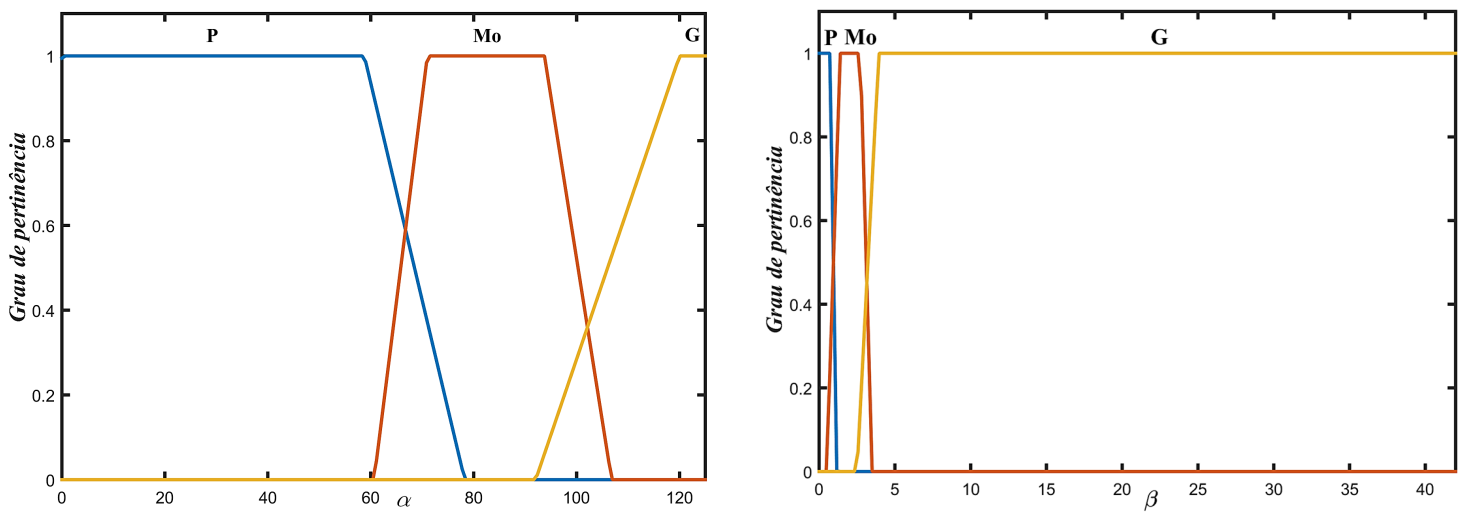

Figura 3: Funções de pertinência das variáveis de entrada. 


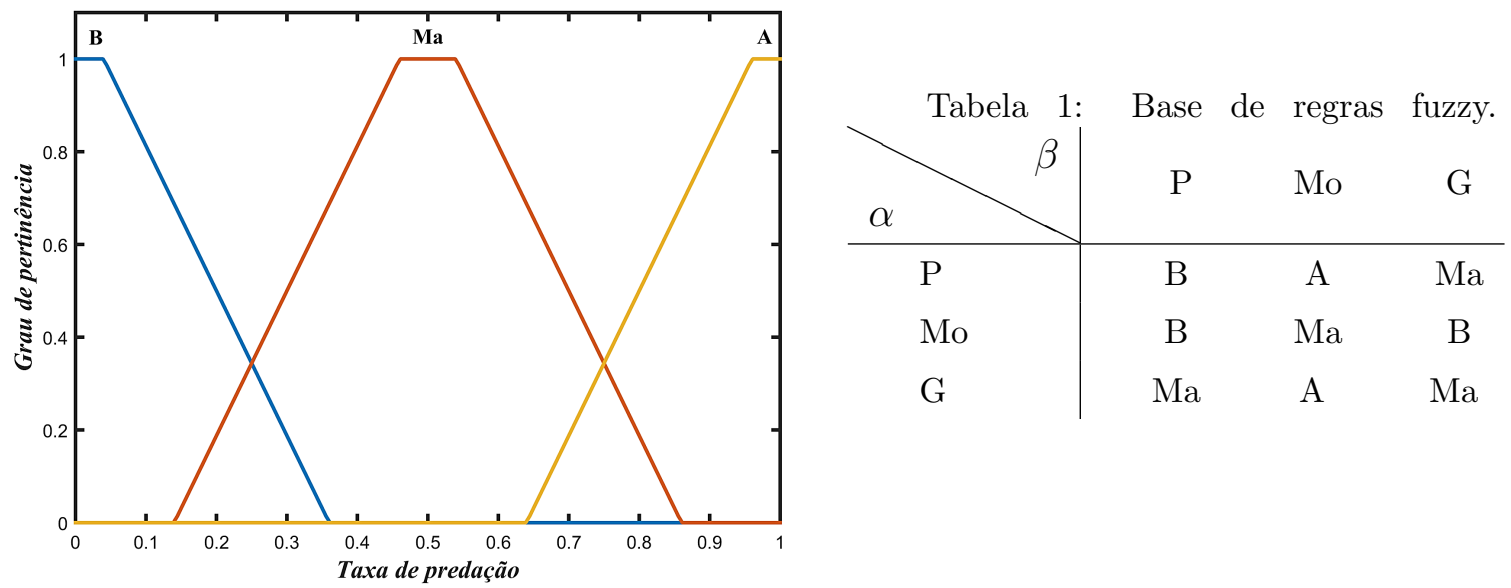

Figura 4: Funções da variável de saída.

\section{Resultados}

A primeira instância e a mais desfiadora da pesquisa tem sido a implementação da codificação do autômato celular tridimensional. As etapas da construção tentaram proceder ou imitar as feitas no autômato celular 2D [9]. A dinâmica é muito mais complexa pela quantidade de vizinhos de uma célula no ambiente 3D, somado ao tamanho do "mar" que aparece (como já afirmado por Dewdney [5]) sensível às mudanças de tamanho. Assim, por tentativas e erros, chegou-se a uma situação de estabilidade aceitável que é o apresentado nesta seção.

Na Figura 5 mostra-se uma das iterações do autômato e as duas espécies interagindo no ambiente natural do mar (em cor azul).

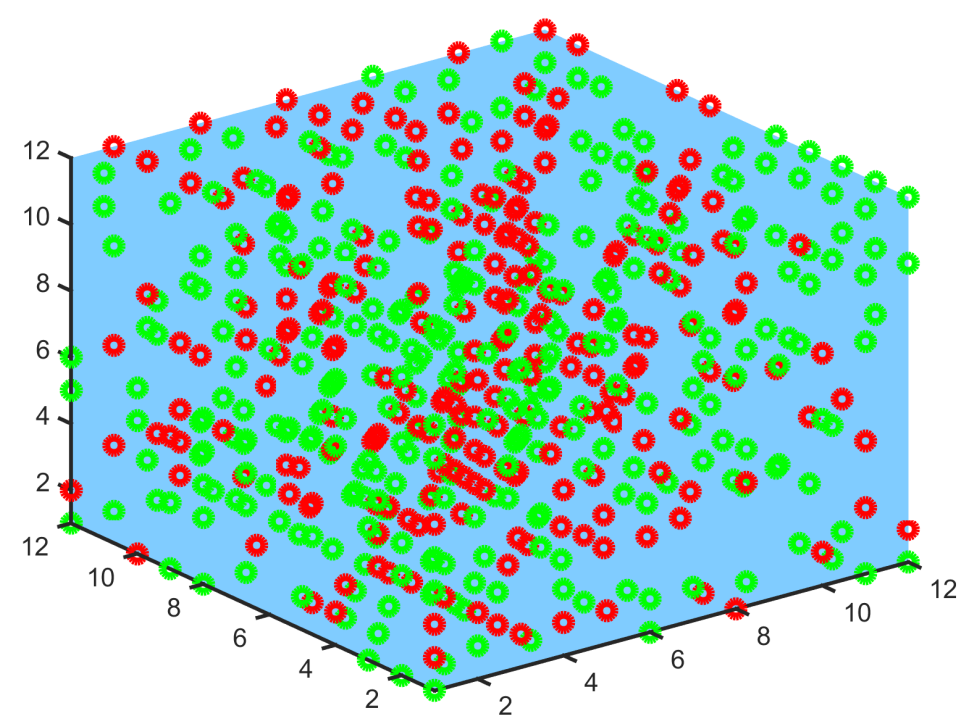

Figura 5: Representação do autômato celular: o azul no fundo é o mar, os peixes são anéis circulares verdes e os tubarões anéis circulares vermelhos. 
Na Figura 6 mostra-se o resultado da dinâmica a partir dos resultados computacionais do autômato celular 3D ao longo do período estudado.

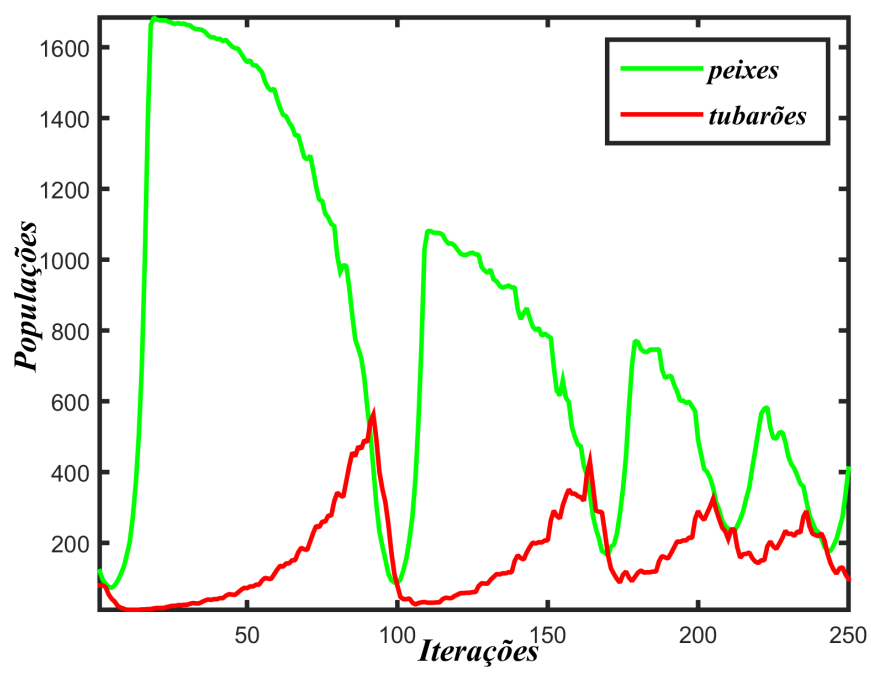

Figura 6: O resultado da dinâmica no período estudado.

Finalmente, na Figura 7 apresenta-se o resultado da dinâmica do autômato 3D representando o plano de fase. Nota-se que a curva obtida tende a um ponto de equilíbrio.

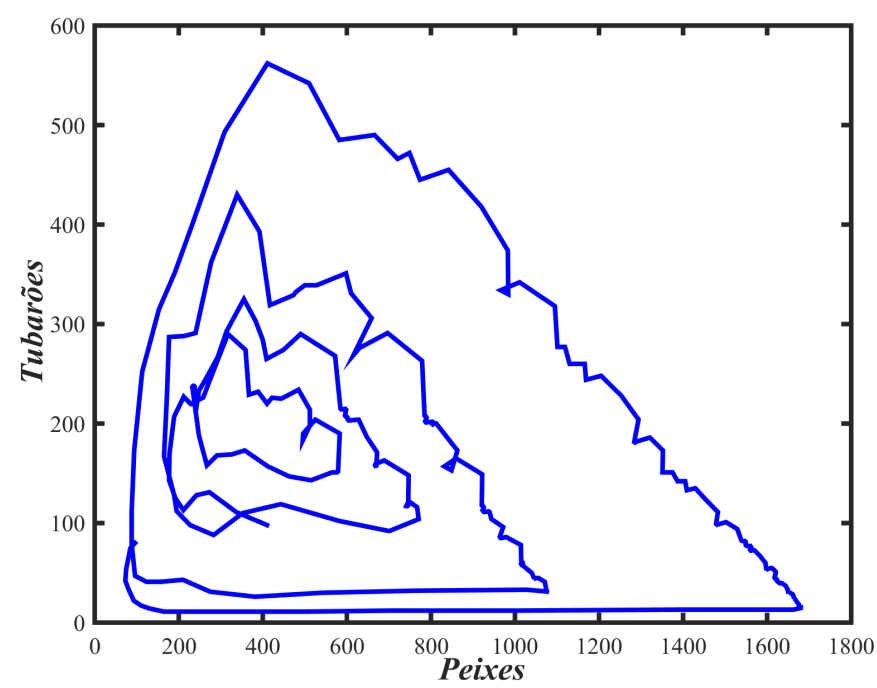

Figura 7: O plano de fase da dinâmica através do autômato celular 3D. 


\section{Conclusão}

Peixes de diferentes espécies (presas e predadores) se movem, comem, se reproduzem, vivem e morrem em um ambiente espacial tridimensional. Essa coexistência é regrada por um algoritmo que reproduz a dinâmica do autômato celular do Wa-Tor. Tal heterogeneidade espacial para a dinâmica populacional exige uma investigação mais complexa e, principalmente, uma abordagem integrada, incorporando uma variedade de técnicas, experimentos e aspectos teóricos que validem a tentativa. Diante disso, surgem os três elementos inovadores desse estudo: a dinâmica populacional de peixes e tubarões inspirada no Wa-Tor; o desenvolvimento de uma base de regras que governa a seleção natural da predação; a abordagem fuzzy que integra a incerteza da toma de decisões.

\section{Referências}

[1] Bays, C. Candidates for the game of life in three dimensions, Complex Systems, 1(3):373-400, 1987.

[2] Bays, C. A Note about the discovery of many new rules for the game of three-dimensional life, Complex Systems, 16(4):381-386, 2006.

[3] Burnie, D. and Wilson, D. Smithsonian institution animal: the definitive visual guide to the world's wildlife, Dorling Kindersley, New York, 2001.

[4] Chen, Q. and Mynett, A. E. Effects of cell size and configuration in cellular automata based prey-predator modelling, Simulation Modelling Practice and Theory, 11:609-625, 2003. DOI:10.1016/j.simpat.2003.08.006.

[5] Dewdney, A. K. Sharks and fish wage an ecological war on the toroidal planet Wa-Tor, Scientific American, 251(6):14-22, 1984.

[6] Dewdney, A. K. The game Life acquires some successors in three dimensions, Scientific American, 256(2):16-24, 1987. DOI:10.1038/scientificamerican0287-16.

[7] Kier, L. B., Seybold, P. G. and Cheng, C. K. Modeling Chemical Systems using Cellular Automata, Springer, Netherlands, 2005.

[8] Jafelice, R. M., Barros, L. C. e Bassanezi, R. C. Teoria dos Conjuntos Fuzzy com Aplicações, 2a edição. SBMAC, 2012. e-ISBN: 978-85-86883-62-0.

[9] Jafelice, R. M. and Nunes, P. S. Studies on Population Dynamics Using Cellular Automata, Cellular Automata, Simplicity Behind Complexity, INTECH, chapter 6, pages 105-130, 2011. ISBN: 978-953-307-230-2.

[10] von Neumann, J. The general and logical theory of automata, Cerebral mechanisms in behavior - The Hixon Symposium, John Wiley \& Sons, New York, pages 1-41, 1951.

[11] Elton, C. S. Fluctuations in the numbers of animals: their causes and effects, Journal of Experimental Biology, 2(1):119-163, 1924. DOI: 10.1242/jeb.2.1.119.

[12] Ermentrout, G.B. and Edelstein K. L. Cellular automata approaches to biological modeling, Journal of Theoretical Biology, 160:97-133, 1993. DOI: 10.1006/jtbi.1993.1007.

[13] n-dimensional torus. Mathcurve. USA 2017. Disponível em: https://mathcurve.com/surfaces.gb/tore/tndim.shtml (copyright ferreol@mathcurve.com) Acessado em abril 2021. 